\section{Current status of musculoskeletal application of shear wave elastography}

\author{
JeongAh Ryu', Woo Kyoung Jeong ${ }^{2}$ \\ 'Department of Radiology, Hanyang University Guri Hospital, Hanyang University School of \\ Medicine, Guri; 'Department of Radiology and Center for Imaging Science, Samsung Medical \\ Center, Sungkyunkwan University School of Medicine, Seoul, Korea
}

Ultrasonography (US) is a very powerful diagnostic modality for the musculoskeletal system due to the ability to perform real-time dynamic high-resolution examinations with the Doppler technique. In addition to acquiring morphologic data, we can now obtain biomechanical information by quantifying the elasticity of the musculoskeletal structures with US elastography. The earlier diagnosis of degeneration and the ability to perform follow-up evaluations of healing and the effects of treatment are possible. US elastography enables a transition from US-based inspection to US-based palpation in order to diagnose the characteristics of tissue. Shear wave elastography is considered the most suitable type of US elastography for the musculoskeletal system. It is widely used for tendons, ligaments, and muscles. It is important to understand practice guidelines in order to enhance reproducibility. Incorporating viscoelasticity and overcoming inconsistencies among manufacturers are future tasks for improving the capabilities of US elastography.

Keywords: Ultrasonography; Elasticity imaging techniques; Tendinopathy; Muscles; Elasticity

\section{Introduction}

As a result of recent advances in ultrasonographic technology, musculoskeletal ultrasonography (US) has become increasingly common in the past decade [1]. Due to its widespread accessibility and relatively low cost, as well as the inherent possibility of real-time dynamic examinations using US, US is an irreplaceable modality in the musculoskeletal field $[2,3]$. The pixel size of the most recent highfrequency probe is as small as one-third of that of 1.5-T magnetic resonance imaging (MRI), so small superficial structures such as tendons, ligaments, and subcutaneous tissues can be better evaluated with US at a higher level of spatial resolution $[3,4]$. Doppler US can detect hyperemia in soft tissue structures $[2,3]$.

Since US has the inherent limitation of not being able to show the biomechanical properties of tissues, it has been difficult to assess the relationship between structural disorganization and clinical pain [5]. Now, with shear wave elastography, in addition to obtaining morphological information, we can quantify the absolute elasticity value of soft tissue structures and obtain useful quantitative information about the mechanical properties related to degeneration, injury, and healing [5]. This technology is the US-based counterpart to the palpation usually done manually by clinicians to

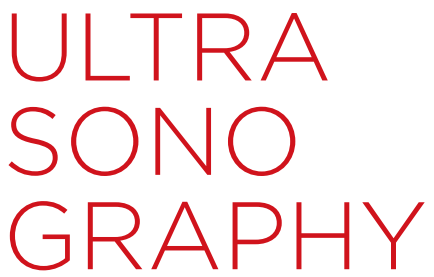

REVIEW ARTICLE

https://doi.org/10.14366/usg. 16053 pISSN: 2288-5919 e elSSN: 2288-5943 Ultrasonography 2017;36:185-197

Received: December 29, 2016

Revised: February 3, 2017

Accepted: February 4, 2017

Correspondence to: JeongAh Ryu, MD, Department of Radiology, Hanyang University Guri Hospital, Hanyang University School of Medicine, 153 Gyeongchun-ro, Guri 11923, Korea

Tel. +82-31-560-2449

Fax. +82-31-560-2551

E-mail: ryuja@hanyang.ac.kr

This is an Open Access article distributed under the terms of the Creative Commons Attribution NonCommercial License (http://creativecommons.org/ licenses/by-nc/3.0/) which permits unrestricted noncommercial use, distribution, and reproduction in any medium, provided the original work is properly cited.

Copyright @ 2017 Korean Society of Ultrasound in Medicine (KSUM)

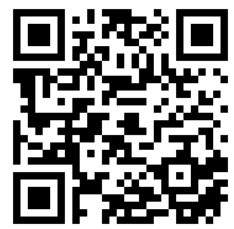

How to cite this article:

Ryu JA, Jeong WK. Current status of musculoskeletal application of shear wave elastography. Ultrasonography. 2017 Jul;36(3): 185-197. 
diagnose and characterize tissue $[6,7]$.

Shear wave elastography involves the following processes: generation of shear waves in tissue by an acoustic radiation force, detection of the propagation of the induced shear waves, and processing of the shear waves to create elastograms, which are quantitative maps of tissue elasticity $[6,7]$.

US elastography has been established as an excellent diagnostic method for liver fibrosis, breast cancer, and thyroid cancer [8-14]. In the musculoskeletal field, much research has been conducted on US elastography since the early 1990s [15], and recently it has been applied to clinical practice [16].

The purpose of this review article is to introduce this technology to musculoskeletal radiologists and to address the current status of US elastography for the musculoskeletal system with an emphasis on shear wave elastography.

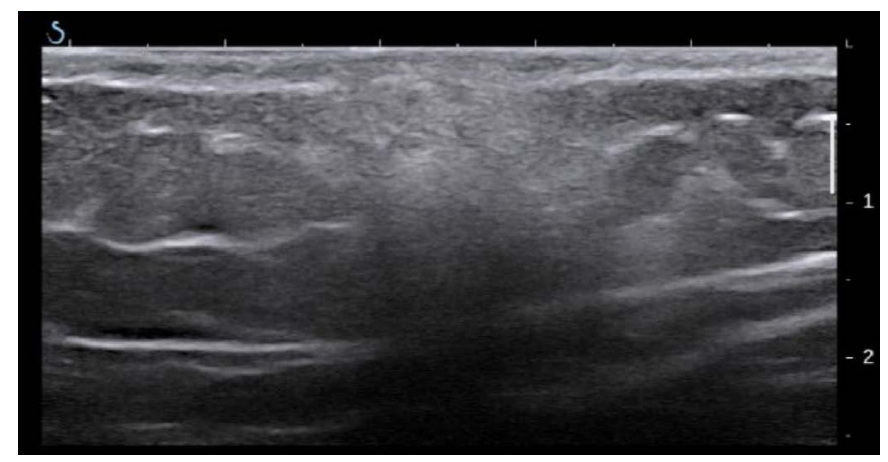

A

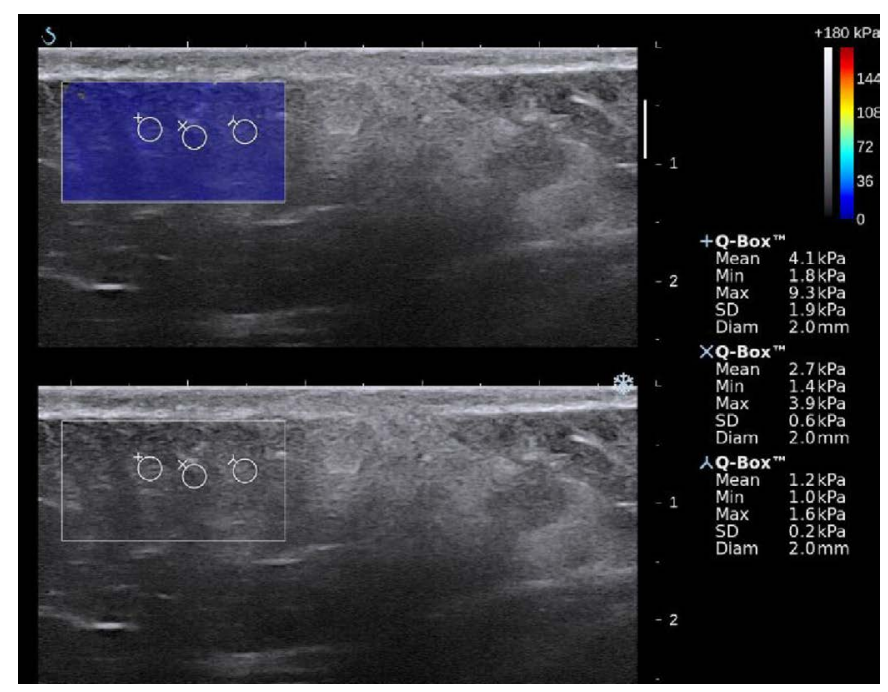

C

Fig. 1. Shear wave elastography of a palpable superficial mass lesion in the right lower quadrant of the abdomen in an 18-year-old man.

A. In the grayscale image, an ill-defined hyperechoic soft tissue lesion with posterior acoustic shadowing was noted. B. The fatty lesion shows increased vascularity in a color Doppler image. C. In shear wave elastography, the adjacent normal subcutaneous fat tissue shows elasticity measured at 1.2-4.1 kPa. D. In the shear wave elastography, the lesion shows much higher elasticity, measured at 18.2-26.8 kPa. 
tissues seen in degeneration or fibrosis [5].

\section{Shear Wave Elastography as the Most Suitable US Elastography Method}

Among the various commercially available US elastography devices, transient elastography does not provide a B-mode image, so the accurate anatomic targeting of elasticity measurement is impossible [10]. Acoustic radiation force impulse imaging produces a grayscale image; however, the region of interest (ROI) is small, and fixed at a depth of $4 \mathrm{~cm}$ [17]. Real-time strain elastography is the most commonly used method and can obtain the tissue elastogram and B-mode image simultaneously; however, it is operator-dependent,

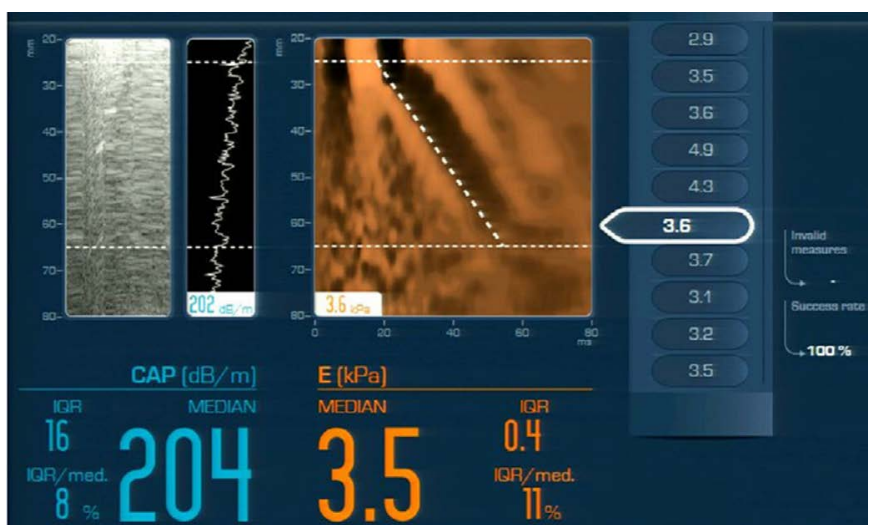

A

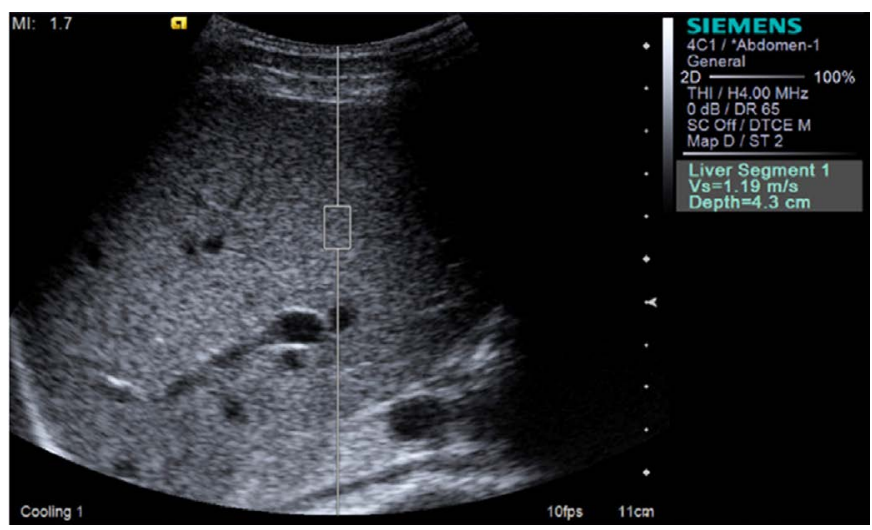

B

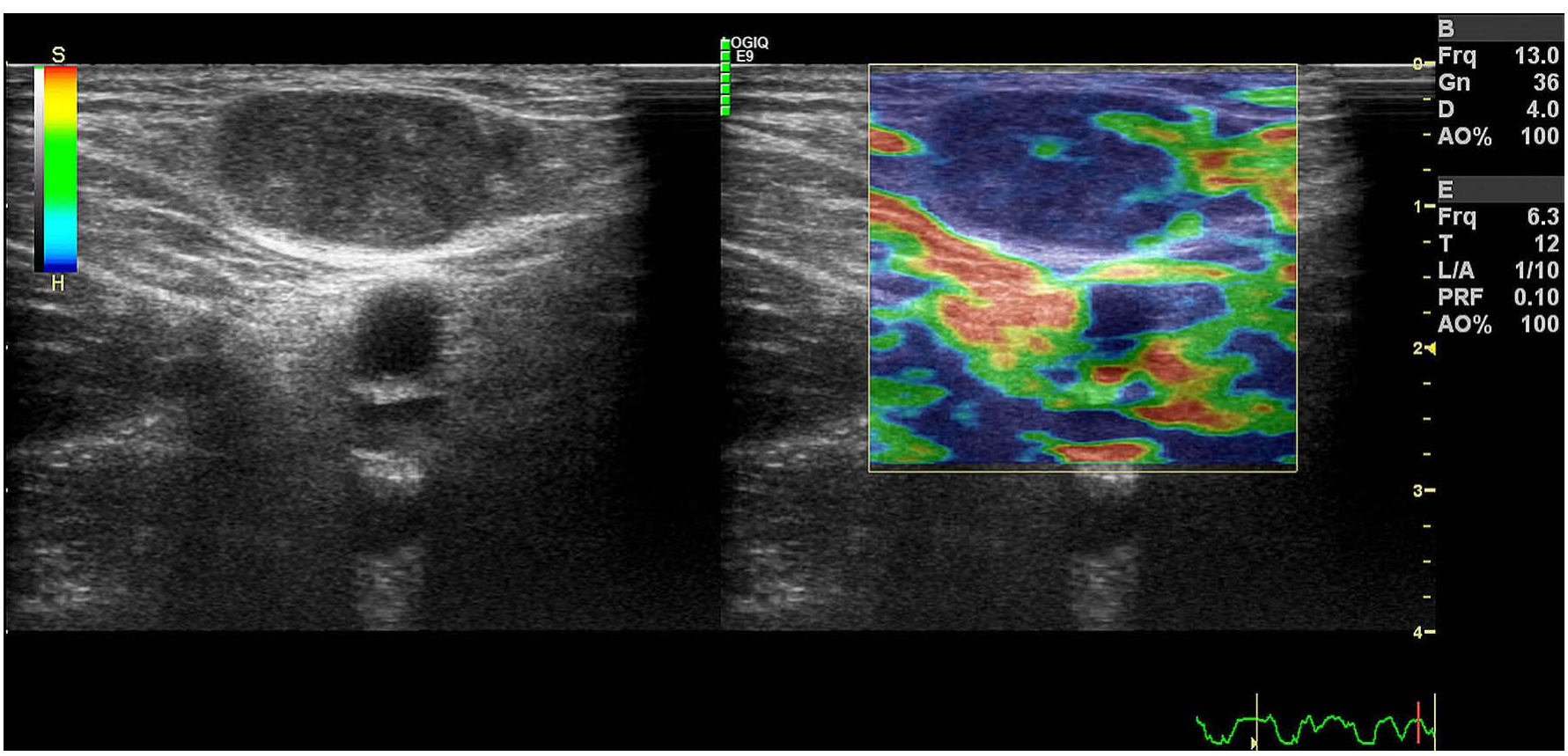

C

Fig. 2. Various techniques of ultrasound elastography.

A. In a transient elastography of a normal liver, the displacement M-mode image located in the center of the monitor shows axial displacement as a function of depth (y-axis) and time (x-axis). Reprinted from Jeong et al. Ultrasonography 2014;33:149-160 [10], according to the Creative Commons licence Korean Society of Ultrasound. B. In an acoustic radiation force impulse imaging of a normal liver, the cylindrical region of interest in the middle of the ultrasonogram was used as the sample. Instead of the Young modulus, the propagating velocity of the shear wave is displayed. Reprinted from Jeong et al. Ultrasonography 2014;33:149-160 [10], according to the Creative Commons licence Korean Society of Ultrasound. C. Strain elastography enables real-time grayscale ultrasonography and a corresponding color map. Reprinted from Kim et al. Ultrasonography 2016;35:104-109 [19], according to the Creative Commons licence Korean Society of Ultrasound. 
and cannot be used to calculate the absolute elastic modulus [1820]. In addition, to obtain the relative strain ratio of tissue, realtime strain elastography needs a reference ROI, which is usually standard subcutaneous fat tissue with constant elasticity; however, in the musculoskeletal system, this is often difficult or impossible to accomplish for anatomic reasons (Fig. 2) $[17,20]$. Shear wave elastography is an operator-independent, relatively reproducible, and quantitative method useful for the evaluation of tendon and muscle [21], in spite of the size, shape, and depth limitations of the currently available ROI [17].

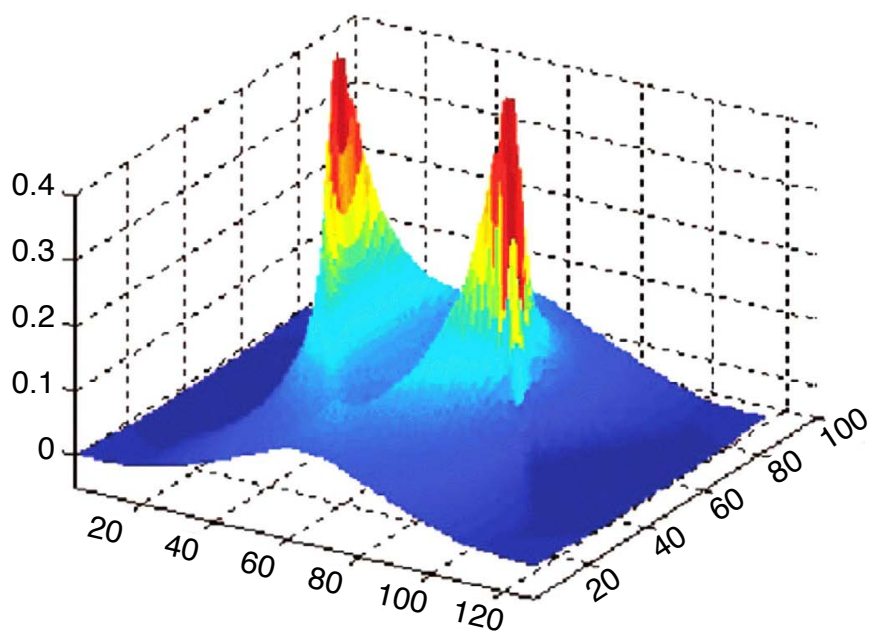

A

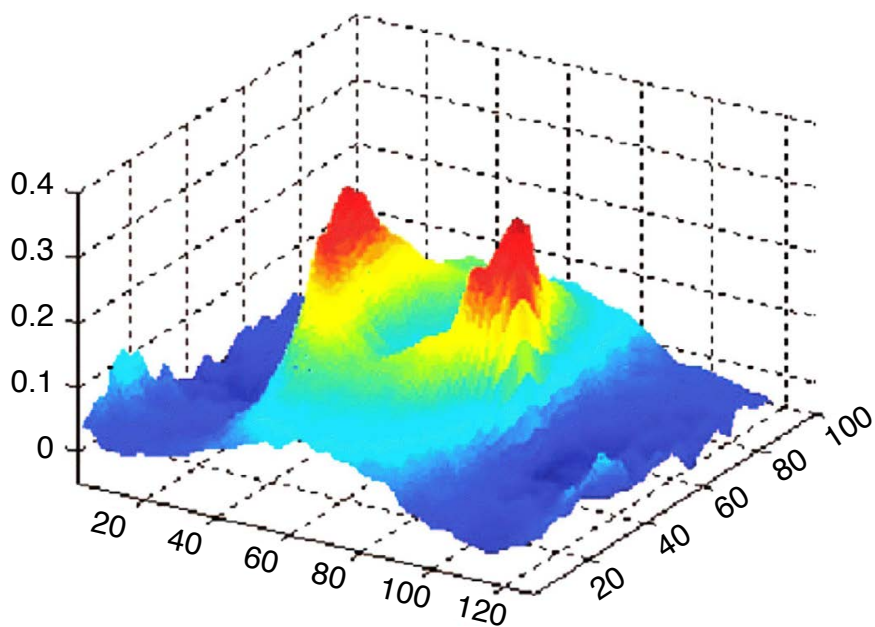

C

Fig. 3. Purely elastic (A), viscoelastic (B), and experimental (C) 3-dimensional plots of the spatial shear wave pattern in the $(x, z)$ plane at a given sampling time.

Plot (D) represents the variation of those three fields along the $x$-axis (at $z=0$ ). Reprinted from Bercoff et al. IEEE Trans Ultrason Ferroelectr Freq Control 2004;51:1523-1536 [22], with permission from the IEEE Xplore Digital Library.
Assumptions of Shear Wave Elastography: Tissue Is Elastic, Homogenous, and Isotropic

Generally, soft tissues are viscoelastic, inhomogeneous, and anisotropic [22]. Viscoelastic tissues have both elastic solid properties and viscous fluid properties (Figs. 3, 4) [6,23]. For elasticity metrics, if the viscous forces are ignored, assuming linear, elastic solid tissues, a first-order approximation is possible $[6,22]$. All commercially available US elastography systems are based on the prerequisite assumption that the material is elastic, incompressible, homogenous, and isotropic $[22,24]$. In fact, the soft tissue elasticity in the human body is nonlinear and dependent on the tissue density, strain magnitude, and/or applied excitation frequency [6].

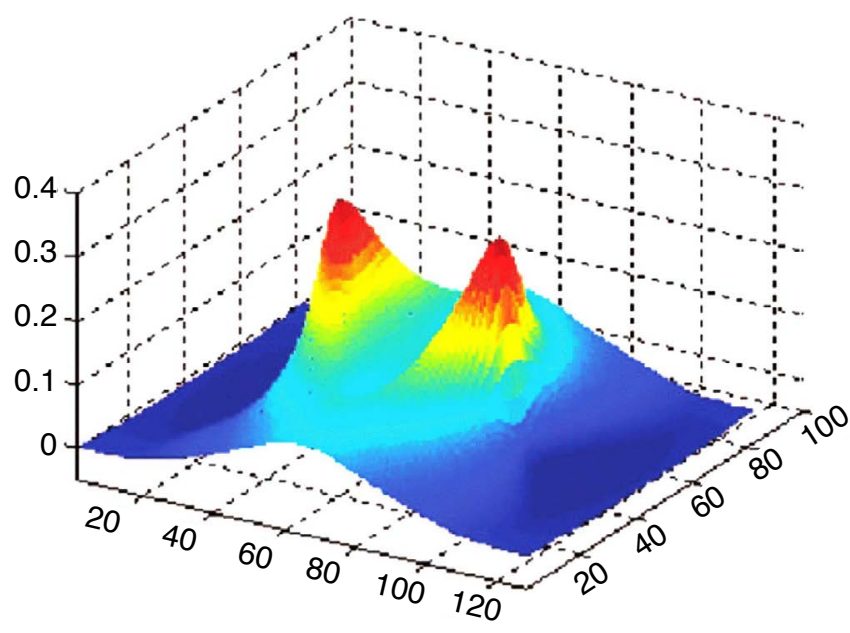

B

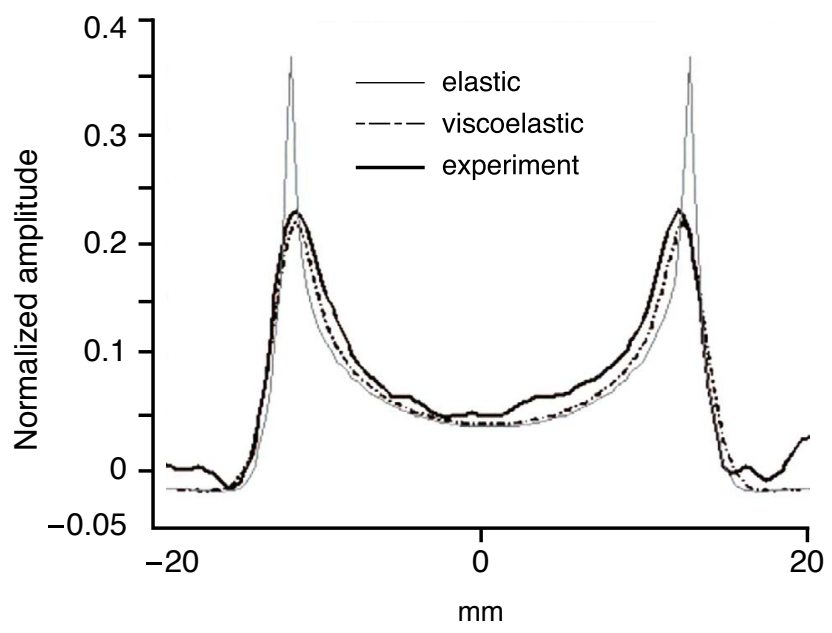

D 
Low viscosity

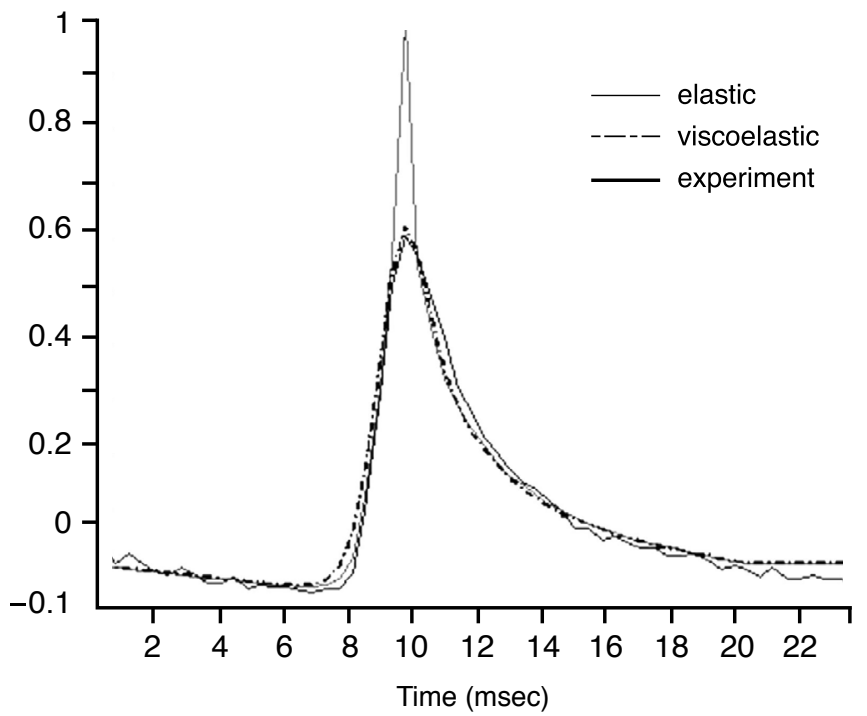

A

Fig. 4. Influence of viscosity on the shear wave temporal shape for a low-viscosity phantom (A) and a high-viscosity phantom (B). Reprinted from Bercoff et al. IEEE Trans Ultrason Ferroelectr Freq Control 2004;51:1523-1536 [22], with permission from the IEEE Xplore Digital Library.

The Young Modulus, Shear Modulus, Shear Wave Speed, and Stiffness

Various elastic moduli are used to define the tissue elasticity $[6,25]$. The elasticity of soft tissue is most commonly reported using the Young modulus $(E)$, which is the resistance of a material to deformation in uniaxial compression or tension $(\mathrm{kPa})$ [6]. The shear modulus $(\mu)$ is the resistance to shear force $(\mathrm{kPa})$ [26]. In soft tissue, two modes of wave propagation occur: longitudinal waves $(C L)$, in which the particles oscillate in the direction of wave propagation; and transverse waves $(C T)$, where the particles oscillate in the direction transverse to the wave propagation. The transverse wave propagation speed is called the shear wave speed (or shear speed, $\mathrm{m} / \mathrm{sec}$ ), and is one of the terms of elastic moduli $[6,16]$. The Young modulus is defined as $E=3 \mu=3 \rho c T^{2}$, where $\rho$ denotes the tissue density [25]. As a result, in tissue with a density not equal to $1.0 \mathrm{~g} / \mathrm{mm}^{3}$, the shear speed is not exactly correlated with the Young modulus. The United States Food and Drug Administration has approved the use of shear speed $(\mathrm{m} / \mathrm{sec})$. Most commercially available US systems are able to display the Young modulus ( $\mathrm{kPa}$ ) [8].

Stiffness is a somewhat different concept from the elastic modulus. It is defined as force over displacement and has units of force per distance. It is a measure of the rigidity of an object, and it is influenced by the elastic modulus of the object itself, shape, and size [27].

\section{Intersystem Variability in Elasticity}

Statistically significant variability has been observed in elasticity quantification according to the vendor system and the depth of the measurements $[28,29]$. Therefore, to ensure reproducibility of the measurements, a patient should be followed using the same US transducer from the same machine, and the threshold values suggested in previous research should not be applied to other systems [28]. For meaningful comparisons of the absolute elasticity of the lesions and the serial assessment of disease states, the sources of variability should first be characterized [27]. The impacts of viscosity and dispersion may be sources of intersystem variability [29].

\section{Clinical Applications of Shear Wave US Elastography to Tendon and Muscle}

\section{Tendons}

Imaging of tendons with US elastography is not easy, and the relevant techniques are still being developed. In recent years, US elastography has been actively applied to tendon imaging in normal healthy volunteers and in individuals with abnormal tendons [30]. Tendon is a very hard tissue in its normal state, and in case of degeneration or injuries, its stiffness can change to various degrees (Fig. 5) [31]. 


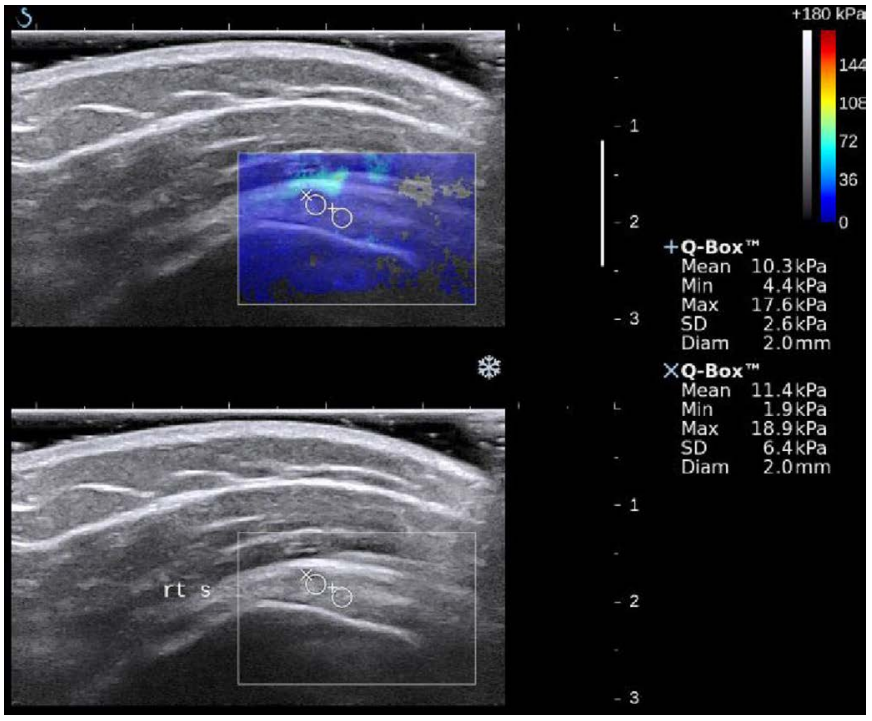

A

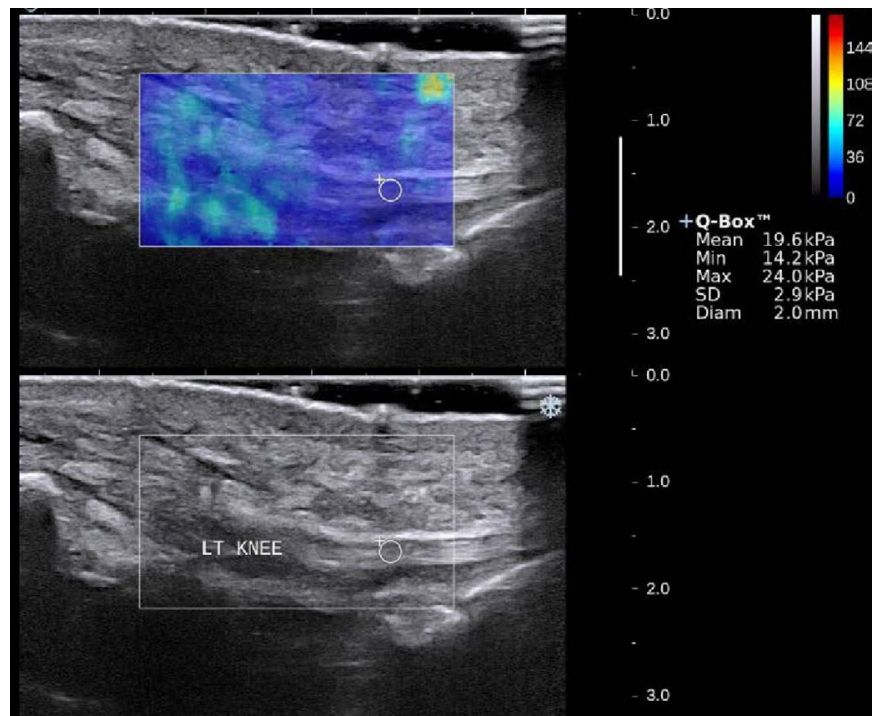

B

Fig. 5. Shear wave elastography of the tendons.

A. The right supraspinatus tendon of a 36-year-old woman shows heterogeneously increased echogenicity in a grayscale image (bottom), suggestive of tendinosis. In shear wave elastography (top), it shows values of 10.3-11.4 $\mathrm{kPa}$, which are relatively low values for the Young modulus. B. The left patellar tendon of an 81-year-old man appears normal in a grayscale image (bottom). In shear wave elastography (top), it shows a homogeneously colored elastogram, and a relatively low value of the Young modulus, measured at $19.6 \mathrm{kPa}$.

The Young modulus of tendon is approximately $400-1,300 \mathrm{kPa}$, and in a normal volunteer study using shear wave elastography, the elasticity of the Achilles tendon was measured as 6-242 $\mathrm{kPa}$ in the neutral position [21], which means the shear wavelengths can be greater than tendon thickness. As a result, guided wave propagation may lead to a false evaluation of the Young modulus, which is the reason that shear wave velocities are usually preferred to Young moduli in tendon imaging $[6,22,32]$. In addition, the high shear wave velocity of hard tendon can exceed the upper limit of measurement of shear wave velocity of the device (maximum scale value) [32,33]. In the Acuson S3000 ultrasound system Virtual Touch imaging quantification (VTIQ; Siemens Medical Solutions, Malvern, PA, USA), the maximum scale value is $10 \mathrm{~m} / \mathrm{sec}$ [33], and in the Imagine Aixplorer system (Supersonic Imagine, Aix-en-Provence, France), it is $16.3 \mathrm{~m} / \mathrm{sec}$ [34].

Due to the high anisotropy, tendon imaging requires the US beam position to be perfectly parallel or perpendicular to the tendon fibers; however, the tendons may have a complex structure due to interpenetration and rotation of fibers from muscles, and sometimes proper positioning of the US beam cannot be achieved [32,33]. Several studies of the Achilles tendon have reported large differences in elasticity values in the transverse (axial) and longitudinal (sagittal) orientations of the probe and the neutral position, extension, and dorsiflexion of the ankle $[32,33,35,36]$.

In a recent study, the shear wave velocity of a normal Achilles tendon in the neutral position was reported to be $15.55 \mathrm{~m} / \mathrm{sec}$ in the sagittal orientation of measurement and $5.29 \mathrm{~m} / \mathrm{sec}$ in the axial orientation, with an anisotropic coefficient of 0.66 ; while ankle plantar flexion was $7.03 \mathrm{~m} / \mathrm{sec}$ in the sagittal orientation and 4.76 $\mathrm{m} / \mathrm{sec}$ in the axial orientation, with an anisotropic coefficient of 0.33 [32].

In another study, in the relaxed position, the shear wave velocity of a normal Achilles tendon was $8.26 \mathrm{~m} / \mathrm{sec}$ in the sagittal orientation, and $4.10 \mathrm{~m} / \mathrm{sec}$ in the axial orientation, with an anisotropic coefficient of 0.50 [33]. The sagittal orientation and the extended tendon position showed markedly higher shear wave velocities in several studies in both normal and abnormal Achilles tendons, which may explain the low intraobserver-interobserver reproducibility and repeatability in many studies $[35,36]$. However, when an ankle fixator was used to standardize the position of the feet and the degree of flexion of ankle and a standardized measurement site was used for the measurement of the Achilles tendon throughout the scanning process, the reproducibility improved [37,38].

Tendinopathy is defined as the various painful conditions occurring from mechanical, degenerative, and overuse diseases, and it is associated with degeneration and disorganization of the collagenous structure, changes in the proteoglycan and water contents, increased cellularity, fatty infiltration, and neovascularization [31].

In one study, the mean elasticity value for normal Achilles tendons 
was approximately $291 \mathrm{kPa}$ (range, 261 to $300 \mathrm{kPa}$ ) and that of ruptured Achilles tendons was approximately $56 \mathrm{kPa}$ (range, 3 to $228 \mathrm{kPa}$ ) in the neutral position [39]. The elastogram map of the normal tendon showed that it was hard and homogeneous, and the ruptured tendon was heterogeneous [39].

The stiffness of the Achilles tendon increases after both static stretching and long-term exercise, especially in the nondominant leg, in frequent exercisers $[37,38]$. This suggests that shear wave elastography can be used to evaluate and follow the effects of exercise in healthy athletes and patients undergoing rehabilitation treatment.

In another study of patients who had undergone surgical repair of a torn Achilles tendon, the repaired tendon elasticity showed a positive correlation with the functional outcome of the tendon during a 48-week follow-up period [40], suggesting that shear wave elastography can be used to evaluate biomechanical information regarding the healing process in Achilles tendons and to predict tendon function (Table 1).

Studies have been carried out of the patellar tendon and other tendons. In Achilles, patellar, and epicondylar tendinopathies, a decrease in tendon stiffness values was correlated with the patients' symptom scores, demonstrating the promise of shear wave elastography during follow-up for tendinopathies. Furthermore, the diagnostic accuracy of tendinopathy has also improved with shear wave elastography [41]. In older patients (61-70 years), the shear wave velocity of the patellar tendon was found to be significantly lower than that of other age groups [42]. The correlation between aging and Achilles tendon stiffness remains controversial.

\section{Muscles}

The use of shear wave elastography to study muscles has increased exponentially in the last few years. Because it allows real-time visualization of muscle stiffness during active or passive muscle movement, shear wave elastography has become the most promising modality for evaluating muscle $[43,44]$. In clinical practice, muscle spasticity in stroke, spinal cord injury, and myopathy has been evaluated through manual palpation, but only in a qualitative and subjective manner. The same has taken place for myofascial pain and in patients undergoing muscle rehabilitation exercises [43].

Dynamic shear wave elastography can dynamically quantify and evaluate isolated individual muscle elasticity during relaxation and contraction (Fig. 6). Muscle stiffness is a very important primary impairment, especially in children with spastic cerebral palsy, because it causes joint motion limitation and fixed contractures.

Shear wave elastography can be used to evaluate and compare the muscles of bilateral limbs, and yield an improved understanding of an individual patient without the need for invasive muscle biopsy or complex lab-based dynamometry, as an extension of the physical exam $[45,46]$.

Studies have sought to develop a reliable protocol for shear wave elastography of muscles to overcome the difficulties in the evaluation of muscles, including voluntary contraction, fatigue and trembling, muscle contraction caused by discomfort, and fatty infiltration of muscles, as well as innately high anisotropy, the variety of positions, and degree of contraction [47].

Various studies have been conducted on muscles. The normal elasticity of muscle during relaxation and contraction has been measured: the values for the tibialis anterior muscle were $40.6 \mathrm{kPa}$ and $268 \mathrm{kPa}$, those of the gastrocnemius muscle were $16.5 \mathrm{kPa}$ and $225 \mathrm{kPa}$, and those of the soleus muscle were $14.5 \mathrm{kPa}$ and 55 $\mathrm{kPa}$, respectively [43]. These results were correlated with magnetic resonance elastography, which reported values of 5-40 $\mathrm{kPa}$ in the resting state, and up to $300 \mathrm{kPa}$ during contraction [48].

The normal value for the shear wave velocity of the supraspinatus

Table 1. Summary of the normal and abnormal ranges of shear wave speed in the Achilles tendon according to the literature

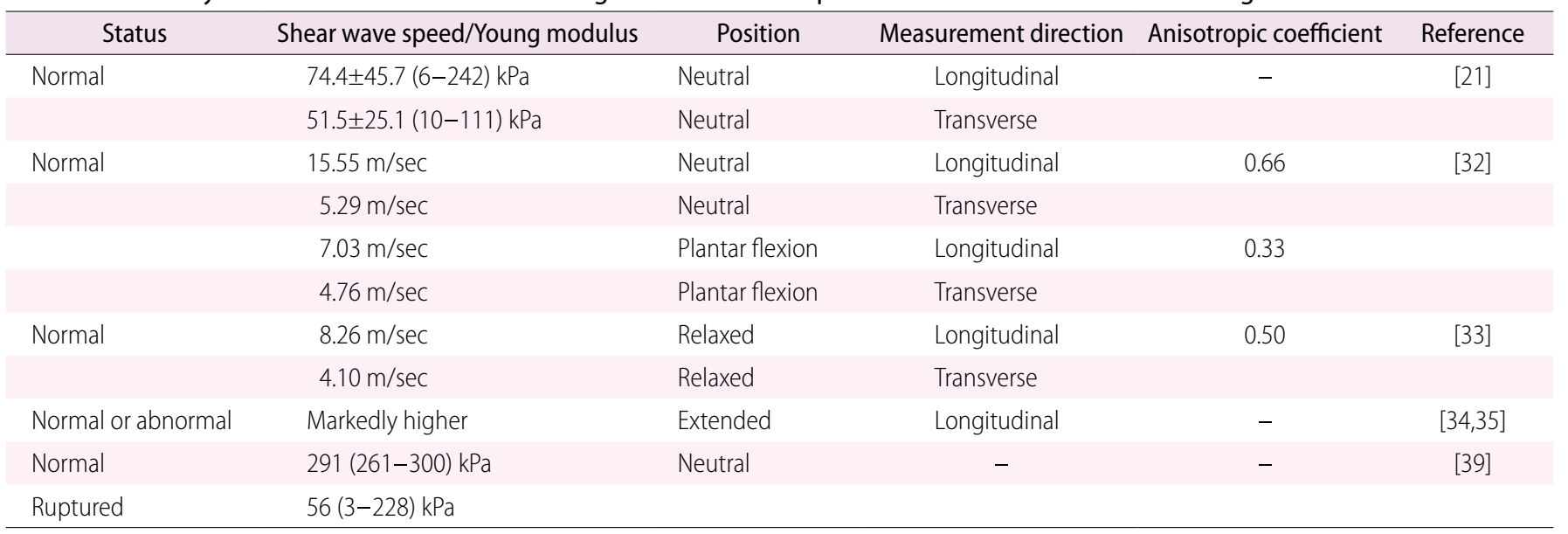




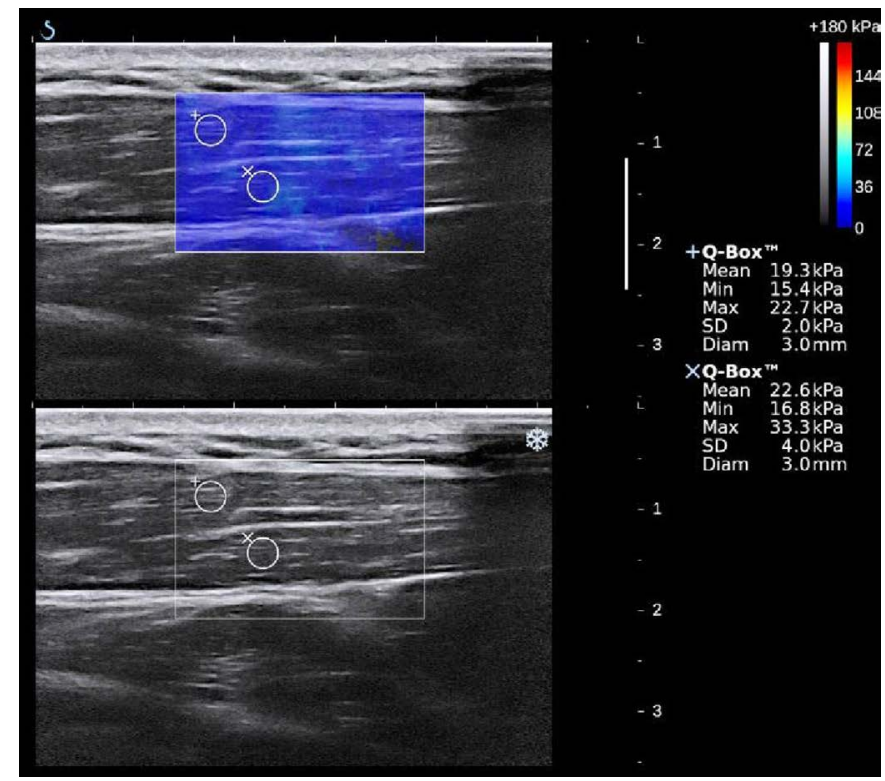

A

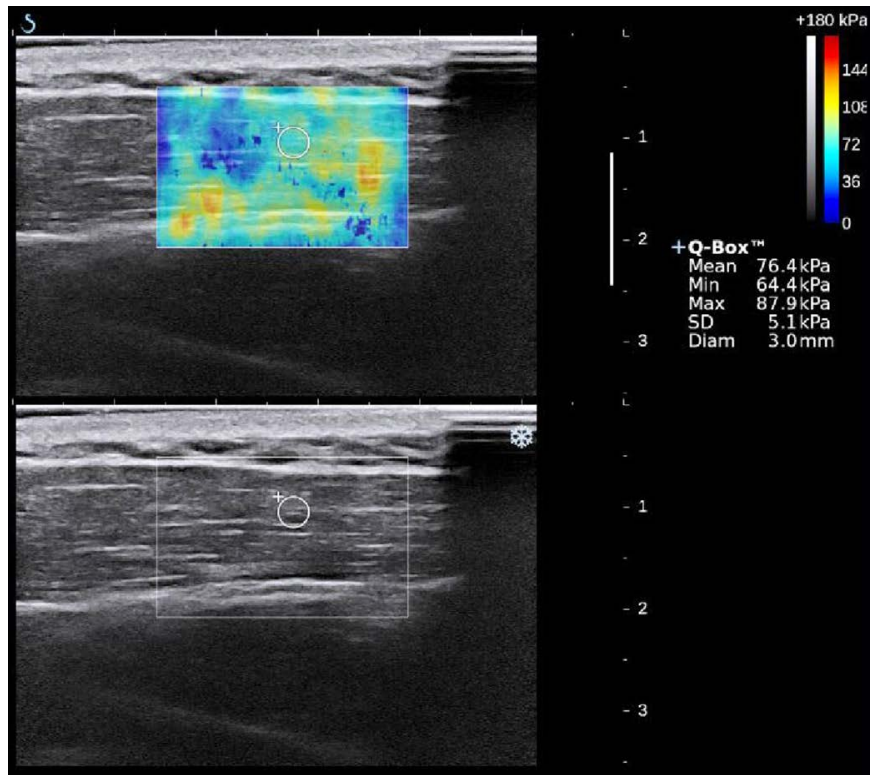

B

Fig. 6. Shear wave elastography of the deltoid muscle of a 49-year-old woman.

A. In the resting state, a homogeneous blue color elastogram is noted in the Q-box. The elasticity was measured at 19.3-22.6 kPa. B. During strain, the deltoid muscle shows markedly increased elasticity, measured at $76.4 \mathrm{kPa}$, and relatively homogeneous yellow in the color elastogram.

muscle was measured to be $3.0 \mathrm{~m} / \mathrm{sec}$ [49]. Among the hamstring muscles, the shear modulus of the semimembranosus was significantly higher than that of other muscles [50]. A study on the passive stretching of a healthy tibialis anterior muscle reported that the Young modulus increased exponentially from 7 to $35 \mathrm{kPa}$, according to the increase in the plantar flexion angle of the ankle [44]. Elongation of the deltoid muscle by an external fixator showed an exponential increase in the Young modulus during passive stretching [51].

The rectus femoris muscle and lateral head of the gastrocnemius muscle have been reported to have a significantly higher Young modulus in younger individuals than in the elderly. No significant difference was found in the soleus muscle between these groups [52].

The supraspinatus muscle showed a shear wave velocity that tended to decrease with fatty infiltration at Goutallier stage III; however, it increased in stage IV [49].

The intraobserver and interobserver reproducibility of shear wave elastography in muscle studies ranged from poor to excellent, but the majority of findings were fair or good $[53,54]$.

In a comparative study of GNE myopathy patients and a healthy group, the shear wave velocity of the muscles was significantly higher in measurements with a transverse orientation and in the deep muscles than in the longitudinal orientation and the superficial muscles. GNE-myopathy patients had significantly lower mean values of shear wave velocity than the normal group, and the serial follow-up evaluation could be used to assess changes in muscle volume and strength in the myopathy group [55].

A study of the effects of prolonged exercise on muscle stiffness showed a significant decrease in the quadriceps shear modulus after 48 hours after exercise compared to baseline [56], likely due to the development of inflammation and muscle swelling. The results suggest the possibility of monitoring physiological and pathological changes in muscles.

In chronic stroke patients, several patterns of shear moduli and torque response associated with passive elbow extension were noted in a recent study [57], and it was simultaneously suggested that wide individual variation was present in passive movement in chronic stroke patients. It was additionally proposed that shear wave elastography has potential as an alternative or complement to electromyographic evaluation [57]. In a study of Parkinson disease patients and a healthy control group, the biceps brachii muscle was measured; symptomatic arms showed a Young modulus of 50.87 $\mathrm{kPa}$ (median value); asymptomatic arms, $40.06 \mathrm{kPa}$; and healthy controls, $23.70 \mathrm{kPa}$ [58].

In children with spastic cerebral palsy, the passive muscle stiffness of the lateral gastrocnemius muscle at different degrees of plantar flexion was investigated [46]. The shear modulus of the muscle was 
Table 2. Summary of the normal and abnormal ranges of shear wave speed of various muscles according to the literature

\begin{tabular}{|c|c|c|c|c|}
\hline Status & Muscle & Shear wave speed/Young modulus & Position & Reference \\
\hline \multirow[t]{6}{*}{ Normal } & Tibialis anterior & $40.6 \mathrm{kPa}$ & Relaxed & [43] \\
\hline & & $268 \mathrm{kPa}$ & Contraction & \\
\hline & Gastrocnemius & $16.5 \mathrm{kPa}$ & Relaxed & \\
\hline & & $225 \mathrm{kPa}$ & Contraction & \\
\hline & Soleus & $14.5 \mathrm{kPa}$ & Relaxed & \\
\hline & & $55 \mathrm{kPa}$ & Contraction & \\
\hline \multirow[t]{2}{*}{ Normal } & Tibialis anterior & $7 \mathrm{kPa}$ & Resting & {$[44]$} \\
\hline & & $35 \mathrm{kPa}$ & Passive stretching & \\
\hline Normal & Supraspinatus & $3.0 \mathrm{~m} / \mathrm{sec}$ & - & [49] \\
\hline \multirow[t]{3}{*}{ Parkinson disease } & Biceps brachii & $50.8 \mathrm{kPa}$ & Symptomatic arm & {$[58]$} \\
\hline & & $40.0 \mathrm{kPa}$ & Asymptomatic arm & \\
\hline & & $23.7 \mathrm{kPa}$ & Healthy control & \\
\hline Children with cerebral palsy & Gastrocnemius lateral head & $15-25 \mathrm{kPa}$ & - & {$[46]$} \\
\hline
\end{tabular}

higher in children with spastic cerebral palsy than in unaffected children, and ranged from 15 to $25 \mathrm{kPa}$ [46].

In medial tibial stress syndrome patients, the shear moduli of the medial head of the gastrocnemius, the lateral head of the gastrocnemius, and the soleus, plantaris, and tibialis anterior muscles were significantly higher than the corresponding values in the normal control group (Table 2) [59].

Recent studies of patients with lower back pain undergoing rehabilitation exercises for trunk stability reported that trunk exercise could improve treatment outcomes because the transversus abdominis muscle contributes to the control of spinal motion. Shear wave elastography could provide real-time feedback during trunk exercise, and more selective measurements of muscles, especially deep muscle, are possible without cross-talk contamination of the adjacent muscles and with reasonable reliability and reproducibility [60].

In an experimental study conducted using calves from cadavers, the muscle shear modulus was significantly reduced by $50 \%$ after removing the covering skin tissues [61], which means that the skin maintains the mechanical properties of the muscle. It has also been reported that the underlying bone had an influence on the shear wave velocity of the overlying muscles [62]. The shear wave velocity decreased significantly with increasing depth and when there was underlying bone below the ROI [62].

\section{The Radiological Society of North America Quantitative Imaging Biomarkers Alliance for Shear Wave US Elastography}

During the past two decades, shear wave elastography has been used in medicine, and several physical misconceptions and nomenclatorial inaccuracies have been noted [27]. For example, Young modulus values are expressed as kilopascals $(\mathrm{kPa})$ and shear wave velocity is expressed in units of speed $(\mathrm{m} / \mathrm{sec})$. To interpret different studies, the most appropriate result may be shear wave velocity [27]. When we use the formula of the Young modulus ( $E=3$ $\mu=3 \rho\left(T^{2}\right), \rho$ is the tissue density and it is assumed to be constant at $1,000 \mathrm{~kg} / \mathrm{m}^{3}$, under the assumption of a purely elastic model, which is valid for isotropic tissues such as the liver or the thyroid gland [25]. However, muscle and tendon are not isotropic or purely elastic, and we should calculate both the elasticity and the viscosity of tendons [32].

Information regarding frequency is also important, because higher-frequency shear waves travel faster, and the viscosity and geometry of soft tissue can cause the shear wave speed to vary with frequency [27]. There are still several questions to resolve regarding shear wave elastography.

In 2008, the Radiological Society of North America created the Quantitative Imaging Biomarkers Alliance (QIBA) with United States federal government representatives (the Food and Drug Administration, National Institutes of Health, and National Institute of Standards and Technology, among others), imaging system manufacturers, pharmaceutical companies, academics, and clinicians to establish guidelines regarding quantitative imaging and the use of imaging biomarkers in clinical practice [29,63-65].

They used standardized ultrasound phantoms and standardized methods to evaluate and understand the sources of bias and variance in shear wave elastography $[29,64-66]$. In recent phantom studies, researchers found statistically significant differences in shear wave speed estimation among systems and according to the 


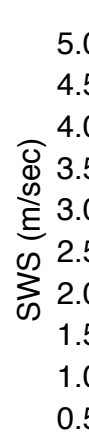

A1

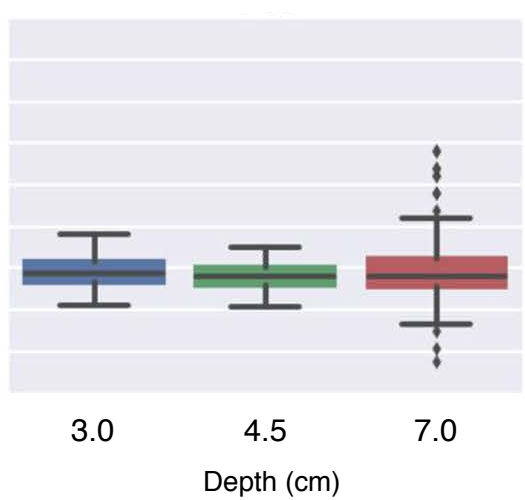

B3

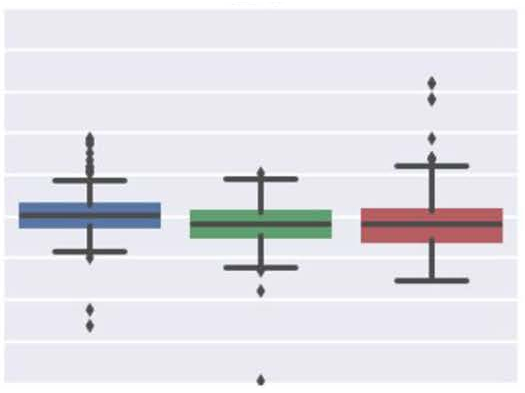

3.0
4.5

Depth $(\mathrm{cm})$
C1

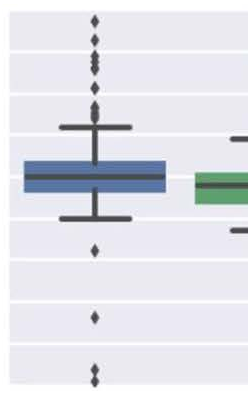

3.0

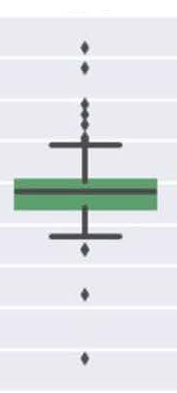

4.5

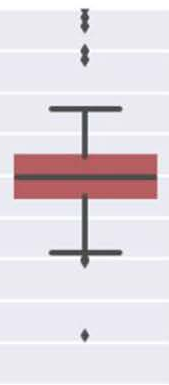

7.0

Depth $(\mathrm{cm})$

Fig. 7. Shear wave ultrasound measurements of multiple centers using multiple vendor systems as a function of phantom and focal depth. The phantoms represent: healthy liver (A1), mildly fibrotic (B3), and significantly fibrotic (C1) tissue. Shear wave speed (SWS) measurement variance increased as a function of higher stiffness $(A 1<B 1<C 1)$ and focal depth $(3 \mathrm{~cm}, 4.5 \mathrm{~cm}$, and $7 \mathrm{~cm})$, which is consistent with the limitations of finite shear wave spatial and temporal sampling, and a decreased signal-to-noise ratio with increasing stiffness and depth. Despite some intersystem variability, current-generation ultrasound SWS imaging systems are able to differentiate viscoelastic material properties ( $\mathrm{P}<0.01$, one-way analysis of variance) spanning healthy to fibrotic liver. Reprinted from Palmeri et al. (2016) RSNA QIBA Ultrasound shear wave speed phase II phantom study in viscoelastic media, with permission from the IEEE Xplore Digital Library [29].

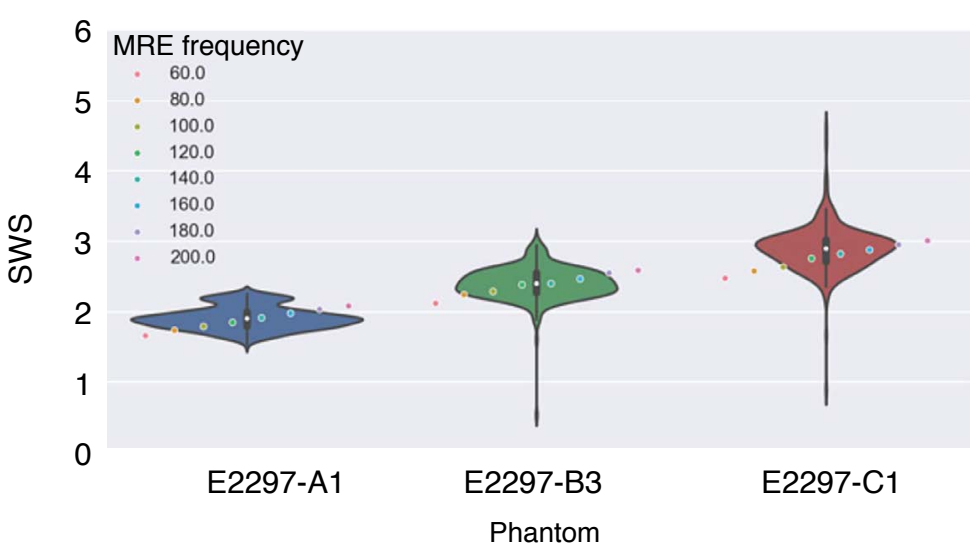

Fig. 8. Violin plots (blue, green, and red) of the distributions of 24 ultrasound (US) elastography shearwave speed (SWS) measurements for each of the three phantoms with the nine ultrasound systems. The multicolor dots show the magnetic resonance elastography (MRE) SWS measurements at eight different shear wave frequencies. The SWS measured by MRE show a linear dependence on shear-wave frequency for all three phantoms. US elastography SWS measurements corresponded most closely to MRE SWS measurements at $140 \mathrm{~Hz}$. Reprinted from Palmeri et al. (2016) RSNA/QIBA Ultrasound Shear Wave Speed Biomarker Committee [69], with permission from the Palmeri et al. and Radiological Society of North America. depth of the object (Fig. 7); the intersystem variability was usually less than $3 \%$ of the shear wave velocity for the typical liver imaging parameters, and in the viscoelastic media it was less than $17.7 \%$ $[29,66,67]$. Several sources of system-dependent bias exist, such as arrival time estimation noise, speckle bias, hardware fluctuations, phase aberration, pulse repetition frequency errors, beamforming errors, and mismatches between the coupling medium and the speed of sound [66].

More recently, the shear wave US viscoelastography method has been developed $[67,68]$. It can be used to quantify shear wave velocity more reliably, considering both the shear storage modulus and the loss modulus in frequency-dependent viscoelastic tissue $[67,68]$.
Researchers also found that US shear wave velocity corresponded to measurements made using magnetic resonance elastography, especially at $140 \mathrm{~Hz}$ (Fig. 8) [69]. The shear wave showed temperature dependence in the viscoelastic phantom, but at room temperature this effect was not significant; and at higher US attenuation, the shear wave velocity showed more biased values [69].

\section{Conclusion}

Shear wave elastography is a promising diagnostic modality for the musculoskeletal system, and the accurate measurement of muscle and tendon elasticity has a major impact in clinical practice. 
The accuracy of measurements is critical for the use of shear wave elastography to diagnose patients, and we should develop a complete understanding of the fundamental properties of this measurement technique.

ORCID: JeongAh Ryu: http://orcid.org/0000-0002-4474-180X; Woo Kyoung Jeong: http://orcid.org/0000-0002-0676-2116

\section{Conflict of Interest}

No potential conflict of interest relevant to this article was reported.

\section{Acknowledgments}

We authors are thankful to Eun Young Cho, So Dam Choi, and Sung Hoon Kim for their dedication to the ultrasonography unit of Hanyang University Guri Hospital.

\section{References}

1. Sharpe RE, Nazarian LN, Parker L, Rao VM, Levin DC. Dramatically increased musculoskeletal ultrasound utilization from 2000 to 2009, especially by podiatrists in private offices. J Am Coll Radiol 2012;9:141-146.

2. Nazarian LN. The top 10 reasons musculoskeletal sonography is an important complementary or alternative technique to MRI. AJR Am J Roentgenol 2008;190:1621-1626.

3. Lee KS. Musculoskeletal sonography of the tendon. J Ultrasound Med 2012;31:1879-1884.

4. Neumann T, Ermert H. Schlieren visualization of ultrasonic wave fields with high spatial resolution. Ultrasonics 2006;44 Suppl 1:e1561-e1566.

5. Docking $\mathrm{SI}$, Ooi CC, Connell D. Tendinopathy: is imaging telling us the entire story? J Orthop Sports Phys Ther 2015;45:842-852.

6. Doherty JR, Trahey GE, Nightingale KR, Palmeri ML. Acoustic radiation force elasticity imaging in diagnostic ultrasound. IEEE Trans Ultrason Ferroelectr Freq Control 2013;60:685-701.

7. Mariappan YK, Glaser KJ, Ehman RL. Magnetic resonance elastography: a review. Clin Anat 2010;23:497-511.

8. Kudo M, Shiina T, Moriyasu F, lijima H, Tateishi R, Yada N, et al. JSUM ultrasound elastography practice guidelines: liver. J Med Ultrason (2001) 2013;40:325-357.

9. Ferraioli $G$, Parekh $P$, Levitov $A B$, Filice $C$. Shear wave elastography for evaluation of liver fibrosis. J Ultrasound Med 2014;33:197-203.

10. Jeong WK, Lim HK, Lee HK, Jo JM, Kim Y. Principles and clinical application of ultrasound elastography for diffuse liver disease. Ultrasonography 2014;33:149-160.

11. Ferraioli G, Filice C, Castera L, Choi BI, Sporea I, Wilson SR, et al. WFUMB guidelines and recommendations for clinical use of ultrasound elastography: Part 3: liver. Ultrasound Med Biol
2015;41:1161-1179.

12. Barr RG, Zhang Z. Shear-wave elastography of the breast: value of a quality measure and comparison with strain elastography. Radiology 2015;275:45-53.

13. Lee SH, Chang JM, Cho N, Koo HR, Yi A, Kim SJ, et al. Practice guideline for the performance of breast ultrasound elastography. Ultrasonography 2014;33:3-10.

14. Kwak JY, Kim EK. Ultrasound elastography for thyroid nodules: recent advances. Ultrasonography 2014;33:75-82.

15. Levinson SF, Shinagawa M, Sato T. Sonoelastic determination of human skeletal muscle elasticity. J Biomech 1995;28:1145-1154.

16. Cosgrove D, Piscaglia F, Bamber J, Bojunga J, Correas JM, Gilja OH, et al. EFSUMB guidelines and recommendations on the clinical use of ultrasound elastography. Part 2: Clinical applications. Ultraschall Med 2013;34:238-253.

17. Klauser AS, Miyamoto H, Bellmann-Weiler R, Feuchtner GM, Wick MC, Jaschke WR. Sonoelastography: musculoskeletal applications. Radiology 2014;272:622-633.

18. Drakonaki EE, Allen GM, Wilson DJ. Ultrasound elastography for musculoskeletal applications. Br J Radiol 2012;85:1435-1445.

19. Kim SJ, Park HJ, Lee SY. Usefulness of strain elastography of the musculoskeletal system. Ultrasonography 2016;35:104-109.

20. De Zordo T, Lill SR, Fink C, Feuchtner GM, Jaschke W, BellmannWeiler $\mathrm{R}$, et al. Real-time sonoelastography of lateral epicondylitis: comparison of findings between patients and healthy volunteers. AJR Am J Roentgenol 2009;193:180-185.

21. Arda K, Ciledag N, Aktas E, Aribas BK, Kose K. Quantitative assessment of normal soft-tissue elasticity using shear-wave ultrasound elastography. AJR Am J Roentgenol 2011;197:532-536.

22. Bercoff J, Tanter M, Muller M, Fink M. The role of viscosity in the impulse diffraction field of elastic waves induced by the acoustic radiation force. IEEE Trans Ultrason Ferroelectr Freq Control 2004;51:1523-1536.

23. Bercoff J, Tanter M, Fink M. Supersonic shear imaging: a new technique for soft tissue elasticity mapping. IEEE Trans Ultrason Ferroelectr Freq Control 2004;51:396-409.

24. Barr RG, Ferraioli G, Palmeri ML, Goodman ZD, Garcia-Tsao G, Rubin J, et al. Elastography assessment of liver fibrosis: Society of Radiologists in Ultrasound Consensus Conference Statement. Radiology 2015;276:845-861.

25. Parker KJ, Fu D, Graceswki SM, Yeung F, Levinson SF. Vibration sonoelastography and the detectability of lesions. Ultrasound Med Biol 1998;24:1437-1447.

26. Youk JH, Son EJ, Park AY, Kim JA. Shear-wave elastography for breast masses: local shear wave speed $(\mathrm{m} / \mathrm{sec})$ versus Young modulus (kPa). Ultrasonography 2014;33:34-39.

27. Urban MW, Nenadic IZ, Chen S, Greenleaf JF. Discrepancies in reporting tissue material properties. J Ultrasound Med 2013;32:886-888. 
28. Franchi-Abella S, Elie C, Correas JM. Ultrasound elastography: advantages, limitations and artefacts of the different techniques from a study on a phantom. Diagn Interv Imaging 2013;94:497501.

29. Palmeri ML, Nightingale $K$, Fielding $S$, Rouze N, Deng $Y$, Lynch $T$, et al. RSNA QIBA Ultrasound shear wave speed phase II phantom study in viscoelastic media. In: 2015 IEEE International Ultrasonics Symposium (IUS); 2015 Oct 21-24; Taipei, Taiwan. Reed Hook, NY: Curran Associates Inc., 2016.

30. Bamber J, Cosgrove D, Dietrich CF, Fromageau J, Bojunga J,

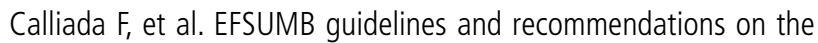
clinical use of ultrasound elastography. Part 1: Basic principles and technology. Ultraschall Med 2013;34:169-184.

31. Weinreb JH, Sheth C, Apostolakos J, McCarthy MB, Barden B, Cote MP, et al. Tendon structure, disease, and imaging. Muscles Ligaments Tendons J 2014;4:66-73.

32. Aubry S, Nueffer JP, Tanter M, Becce F, Vidal C, Michel F. Viscoelasticity in Achilles tendonopathy: quantitative assessment by using real-time shear-wave elastography. Radiology 2015;274:821829.

33. Fu S, Cui L, He X, Sun Y. Elastic characteristics of the normal Achilles tendon assessed by virtual touch imaging quantification shear wave elastography. J Ultrasound Med 2016;35:1881-1887.

34. Martin JA, Biedrzycki AH, Lee KS, DeWall RJ, Brounts SH, Murphy $W L$, et al. In vivo measures of shear wave speed as a predictor of tendon elasticity and strength. Ultrasound Med Biol 2015;41:27222730.

35. Aubry S, Risson JR, Kastler A, Barbier-Brion B, Siliman G, Runge $\mathrm{M}$, et al. Biomechanical properties of the calcaneal tendon in vivo assessed by transient shear wave elastography. Skeletal Radiol 2013;42:1143-1150.

36. Peltz CD, Haladik JA, Divine G, Siegal D, van Holsbeeck M, Bey MJ. ShearWave elastography: repeatability for measurement of tendon stiffness. Skeletal Radiol 2013;42:1151-1156.

37. Chiu TC, Ngo HC, Lau LW, Leung KW, Lo MH, Yu HF, et al. An investigation of the immediate effect of static stretching on the morphology and stiffness of Achilles tendon in dominant and nondominant legs. PLoS One 2016;11:e0154443.

38. Siu WL, Chan CH, Lam CH, Lee CM, Ying M. Sonographic evaluation of the effect of long-term exercise on Achilles tendon stiffness using shear wave elastography. J Sci Med Sport 2016;19:883-887.

39. Chen XM, Cui LG, He P, Shen WW, Qian YJ, Wang JR. Shear wave elastographic characterization of normal and torn achilles tendons: a pilot study. J Ultrasound Med 2013;32:449-455.

40. Zhang LN, Wan WB, Wang YX, Jiao ZY, Zhang LH, Luo YK, et al. Evaluation of elastic stiffness in healing Achilles tendon after surgical repair of a tendon rupture using in vivo ultrasound shear wave elastography. Med Sci Monit 2016;22:1186-1191.

41. Dirrichs $T$, Quack V, Gatz M, Tingart M, Kuhl CK, Schrading S. Shear wave elastography (SWE) for the evaluation of patients with tendinopathies. Acad Radiol 2016;23:1204-1213.

42. Hsiao MY, Chen YC, Lin CY, Chen WS, Wang TG. Reduced patellar tendon elasticity with aging: in vivo assessment by shear wave elastography. Ultrasound Med Biol 2015;41:2899-2905.

43. Shinohara M, Sabra K, Gennisson JL, Fink M, Tanter M. Realtime visualization of muscle stiffness distribution with ultrasound shear wave imaging during muscle contraction. Muscle Nerve 2010;42:438-441.

44. Koo TK, Guo JY, Cohen JH, Parker KJ. Quantifying the passive stretching response of human tibialis anterior muscle using shear wave elastography. Clin Biomech (Bristol, Avon) 2014;29:33-39.

45. Bar-On L, Slane LC. Shear wave elastography for the assessment of muscle stiffness in children with CP: insights and challenges. Dev Med Child Neurol 2016;58:1209-1210.

46. Brandenburg JE, Eby SF, Song P, Kingsley-Berg S, Bamlet W, Sieck GC, et al. Quantifying passive muscle stiffness in children with and without cerebral palsy using ultrasound shear wave elastography. Dev Med Child Neurol 2016;58:1288-1294.

47. Dubois $G$, Kheireddine W, Vergari C, Bonneau D, Thoreux P, Rouch $P$, et al. Reliable protocol for shear wave elastography of lower limb muscles at rest and during passive stretching. Ultrasound Med Biol 2015;41:2284-2291.

48. Basford JR, Jenkyn TR, An KN, Ehman RL, Heers G, Kaufman KR. Evaluation of healthy and diseased muscle with magnetic resonance elastography. Arch Phys Med Rehabil 2002;83:15301536.

49. Rosskopf AB, Ehrmann C, Buck FM, Gerber C, Fluck M, Pfirrmann CW. Quantitative shear-wave US elastography of the supraspinatus muscle: reliability of the method and relation to tendon integrity and muscle quality. Radiology 2016;278:465-474.

50. Nakamura M, Hasegawa S, Umegaki H, Nishishita S, Kobayashi T, Fujita $K$, et al. The difference in passive tension applied to the muscles composing the hamstrings: comparison among muscles using ultrasound shear wave elastography. Man Ther 2016;24:1-6.

51. Hatta T, Giambini H, Sukegawa K, Yamanaka Y, Sperling JW, Steinmann SP, et al. Quantified mechanical properties of the deltoid muscle using the shear wave elastography: potential implications for reverse shoulder arthroplasty. PLoS One 2016;11:e0155102.

52. Akagi R, Yamashita Y, Ueyasu Y. Age-related differences in muscle shear moduli in the lower extremity. Ultrasound Med Biol 2015;41:2906-2912.

53. Umegaki H, Ikezoe T, Nakamura M, Nishishita S, Kobayashi T, Fujita $\mathrm{K}$, et al. The effect of hip rotation on shear elastic modulus of the medial and lateral hamstrings during stretching. Man Ther 2015;20:134-137.

54. Cortez CD, Hermitte L, Ramain A, Mesmann C, Lefort T, Pialat JB. Ultrasound shear wave velocity in skeletal muscle: a reproducibility study. Diagn Interv Imaging 2016;97:71-79. 
55. Carpenter EL, Lau HA, Kolodny EH, Adler RS. Skeletal muscle in healthy subjects versus those with GNE-related myopathy: evaluation with shear-wave US: a pilot study. Radiology 2015;277:546554.

56. Andonian P, Viallon M, Le Goff C, de Bourguignon C, Tourel C, Morel J, et al. Shear-wave elastography assessments of quadriceps stiffness changes prior to, during and after prolonged exercise: a longitudinal study during an extreme mountain ultra-marathon. PLoS One 2016;11:e0161855.

57. Eby $S$, Zhao H, Song P, Vareberg BJ, Kinnick R, Greenleaf JF, et al. Quantitative evaluation of passive muscle stiffness in chronic stroke. Am J Phys Med Rehabil 2016;95:899-910.

58. Du LJ, He W, Cheng LG, Li S, Pan YS, Gao J. Ultrasound shear wave elastography in assessment of muscle stiffness in patients with Parkinson's disease: a primary observation. Clin Imaging 2016;40:1075-1080.

59. Akiyama K, Akagi R, Hirayama K, Hirose N, Takahashi H, Fukubayshi $\mathrm{T}$. Shear modulus of the lower leg muscles in patients with medial tibial stress syndrome. Ultrasound Med Biol 2016;42:1779-1783.

60. MacDonald D, Wan A, McPhee M, Tucker K, Hug F. Reliability of abdominal muscle stiffness measured using elastography during trunk rehabilitation exercises. Ultrasound Med Biol 2016;42:10181025.

61. Yoshitake Y, Miyamoto N, Taniguchi K, Katayose M, Kanehisa H. The skin acts to maintain muscle shear modulus. Ultrasound Med Biol 2016;42:674-682.

62. Ewertsen C, Carlsen JF, Christiansen IR, Jensen JA, Nielsen MB. Evaluation of healthy muscle tissue by strain and shear wave elastography: dependency on depth and ROI position in relation to underlying bone. Ultrasonics 2016;71:127-133.

63. Sullivan DC, Obuchowski NA, Kessler LG, Raunig DL, Gatsonis C, Huang $E P$, et al. Metrology standards for quantitative imaging biomarkers. Radiology 2015;277:813-825.

64. Nightingale KR, Rouze NC, Rosenzweig SJ, Wang MH, Abdelmalek $M F$, Guy $C D$, et al. Derivation and analysis of viscoelastic properties in human liver: impact of frequency on fibrosis and steatosis staging. IEEE Trans Ultrason Ferroelectr Freq Control 2015;62:165175.

65. Palmeri ML, Feltovich H, Homyk AD, Carlson LC, Hall TJ. Evaluating the feasibility of acoustic radiation force impulse shear wave elasticity imaging of the uterine cervix with an intracavity array: a simulation study. IEEE Trans Ultrason Ferroelectr Freq Control 2013;60:2053-2064.

66. Deng Y, Rouze NC, Palmeri ML, Nightingale KR. On systemdependent sources of uncertainty and bias in ultrasonic quantitative shear-wave imaging. IEEE Trans Ultrason Ferroelectr Freq Control 2016;63:381-393.

67. Palmeri ML. System-dependent factors influencing shear wave speed measurements for liver fibrosis characterization. AIUM Webinar Series [Internet]. Laurel, MD: American Institute of Ultrasound in Medicine, 2016 [cited 2016 Jul 29]. Available from: http://www.aium.org/cme/testsWebinar.aspx.

68. Kazemirad S, Bernard S, Hybois S, Tang A, Cloutier G. Ultrasound shear wave viscoelastography: model-independent quantification of the complex shear modulus. IEEE Trans Ultrason Ferroelectr Freq Control 2016;63:1399-1408.

69. Palmeri M, Urban MW, Wear KA, Chen J, Dhyani M, Alam SK, et al. RSNA/QIBA Ultrasound Shear Wave Speed Biomarker Committee. QIBA posters from RSNA 2016 Annual Meeting. US SWS Poster. 102nd Scientific Assembly and Annual Meeting [Internet]. Oak Brook, IL: Radiological Society of North America, 2016 [cited 2016 Nov 26]. Available from: http://qibawiki.rsna.org/images/3/3a/US_ SWS_Poster2016.pdf. 